\title{
The Effect of Chamomile Tea on Anxiety and Depression in Cancer Patients Treated with Chemotherapy
}

\author{
Vahid Moeini Ghamchini ${ }^{1}$, Majid Salamiं ${ }^{2}$, Gholam Reza Mohammadi' ${ }^{\text {, Zahra Moradi }}{ }^{3}$, Ali Kavosi ${ }^{4}$, Ali Movahedi $^{5}$, Mohammad Bidkhori $^{6}$, \\ Mohammad Reza Aryaeefar ${ }^{7, *}$ \\ 'Department of Operating Room, Neyshabur University of Medical Sciences, Neyshabur, IRAN. \\ 'Medical Oncologist and Hematologist, Faculty of Medicine, Shahrood University of Medical Sciences, Shahrood, IRAN. \\ ${ }^{3}$ Department of Nursing, Alborz University of Medical Sciences, Alborz, IRAN. \\ ${ }^{4}$ Department of Nursing, Nursing Research Center, Golestan University of Medical Sciences, Gorgan, IRAN. \\ ${ }^{5}$ Department of Anesthesia, Neyshabur University of Medical Sciences, Neyshabur, IRAN. \\ ${ }^{6}$ Department of public health, Neyshabur University of Medical Sciences, Neyshabur, IRAN. \\ 'Department of Operating Room, Neyshabur University of Medical Sciences, Neyshabur, IRAN.
}

\begin{abstract}
Objectives: Natural products such as chamomile have been used throughout the world for centuries as alternative medicines or functional food. Chamomile (Matricaria chamomilla L.) has been applied for centuries as an herbal remedy for treat various inflammatory conditions such as eczema, ulcers, gout, neuralgia and rheumatic pains. Materials and Methods: This study was a single blind clinical trial. The samples will be placed in two groups of intervention ( 55 people) and control ( 55 people) by convenient sampling and random blocked. In the study, level of anxiety and depression in patients were measured in both groups by anxiety and depression questionnaires. Results: The mean of depression scores before and after the intervention in the intervention group was 25.81 and 19.49 , respectively. Mean score of depression before and after intervention was 25.83 and 24.90 in control group. Results shows the mean scores of depression before and after intervention in the intervention and control group were
\end{abstract}

difference significantly $(p<0.001)$. Conclusion: Chamomile tea can be used as an alternative treatment to depression therapy in cancer patients undergoing chemotherapy due to its low, safe, simple and affordable side effects. Chamomile tea is recommended for cancer patients undergoing chemotherapy as an effective way to reduce symptoms of depression. Key words: Anxiety, Chamomile tea, Chemotherapy, Cancer, Depression 1.

Correspondence

Mohammad Reza Aryaeefar,

Msc of Critical Care Nursing, Department of Operating Room, Neyshabur University of Medical Sciences, Neyshabur, IRAN.

Phone: +989150065246

Email: Aryaeefarm1@nums.ac.ir

DOI: 10.5530/jyp.2019.11.62

\section{INTRODUCTION}

Although the total numbers of patients with cancer continue to raise worldwide, new therapies have protracted the 5-year survival rates substantially. ${ }^{1,2}$ A diagnose and survival improving, quality of life issue has become increasingly significant, because of greater numbers of patients. ${ }^{3}$ Quality of life considerations are serious both for the estimation of new therapeutic regimens and for the progress of overall disease management strategies. ${ }^{4}$ To estimate the net benefits related with the use of chemotherapy, one must have a comprehensive knowledge of not only treatment effectiveness, but also side effects such as heir likelihood, their determination and their potential to enhance emotional distress and to disturb the activities of daily living. ${ }^{5}$ The another factors that is important to recognize the extent to which patient assessments of treatment distress and disruption including direct drug impact, especially those factors that are topic to the control of the practitioner. ${ }^{6}$ This knowledge will be vital for cases in which the costs and benefits of chemotherapy are considered to be of the same magnitude. This includes cases where the negative consequences of chemotherapy are severe enough to reduce the benefits of longevity or to lead the patient to quit treatment or to seek to decrease the intensity of therapy, actions that in some circumstances may be directly correlated to survival. ${ }^{7}$ The most common emotional responses in cancer patients are anxiety, depression and anger. However, he further noted that some of these responses may be considered as a natural response to those exposed to stressful situations. ${ }^{8}$
Natural products such as chamomile have been used throughout the world for centuries as alternative medicines or functional foods. ${ }^{9}$ Chamomile (Matricaria chamomilla L.) has been applied for centuries as an herbal remedy for treat various inflammatory conditions such as eczema, ulcers, gout, neuralgia and rheumatic pains. Chamomile flowers contain 1-2\% volatile oils including a-bisabolol, a-bisabolol oxides A and $\mathrm{B}$ and matricin (usually converted to chamazulene) as well as other flavonoids that possess anti-inflammatory and antiphlogistic properties and often classified according to their polarity. The chamomile drug is included in the pharmacopoeia of 26 countries. ${ }^{10,11}$

While several studies have stated the sedative effects of chamomile, there have been few studies published on the effect of Chamomile tea on anxiety and depression. The present study is the first study known to the authors to explore the effects of chamomile tea on anxiety and depression in cancer patients treated with chemotherapy.

\section{MATERIALS AND METHODS}

\section{Study design}

This study was a single blind clinical trial. So that the nurses who helped us to fill out a questionnaire did not know that people are in which group. In the end, the questionnaires were presented to the statistics professor without mentioning the codes and codes having between 1 and 110. The 
study population included cancer patients visiting to the department of chemotherapy at 22 Bahman Hospital in Neishabour. In this study, the sampling was easy and accessible so that all patients who were willing to participate in this study were used. A patient selected among all patients that visited to the chemotherapy department of 22 Bahman hospital in Neyshabur. Patients were randomly divided into intervention and control groups. It should be noted that the samples will be placed in two groups of intervention ( 55 people) and control ( 55 people) by convenient sampling and random blocked after taking the consent criteria (consent form to participation in the research project) and filling in the questionnaire (To assess anxiety, depression and demographic information) by the researcher.

The sample size was calculated using power analysis for independent t-test. The sample size is determined in two groups of 100 patients considering the alpha value of 0.05 , the study power of $80 \%$, the maximum effect size of $50 \%$ and referring to the Altman table, which is considered total sample size of 110 patients based on $10 \%$ attrition.

\section{Intervention}

At the beginning of the study, level of anxiety and depression in patients were measured in both groups by anxiety and depression questionnaires. Then, according to similar studies, the intervention group was asked to use chamomile tea once a day for 2 weeks. During the treatment period, patients are encouraged to drink chamomile tea on a weekly by SMS, to avoid forgetfulness in the use of the drug.

\section{Outcome measures}

The questionnaires were two parts. The first part of the demographic information includes the name, gender, age, education, marital status, type of cancer and occupation. The second part was anxiety and depression questionnaires. The Beck Anxiety Inventory was introduced in 1990 by Aaron Temkin Beck and his colleagues who specifically assess the severity of clinical symptoms in individuals. The questionnaire is a 21-point scale in which a subject in each subject chooses one of four options that indicates the severity of her anxiety. Each question has four options range from 0 to 3 scored four part. The total score on the questionnaire are range from 0 to 63 . This questionnaire has a high validity, its internal consistency coefficient (alpha coefficient) is $92 \%$, its reliability is 0.75 with a one-week trial and the correlation of its materials varies from 0.07 to $0.76 .^{12}$

\section{Ethical considerations}

This study was done after approval by the Research Council and the Ethics Council of the Neyshabur Medical Faculty. We emphasized that participation in this study was voluntary and that refusing to participate would not affect their rights in any way. Those who agreed to participate signed a consent form.

\section{Data analysis}

The SPSS (version 21) statistical software package was applied to analyses the data. Demographic characteristics and questionnaire data were reported using descriptive statistics, including percentage, frequency, mean and standard deviation. Two-sample t-tests were used to examine the mean differences in anxiety and depression between the two groups (See consort flow diagram 1).

\section{RESULTS}

A total of 110 patient's cancer (61 males and 49 female) were enrolled in this study. Valid data were obtained from 55 participants in the experimental group (age range: 24-69 years) and 55 participants in the control group (age range: 25-69 years). The majority of patients had diploma or

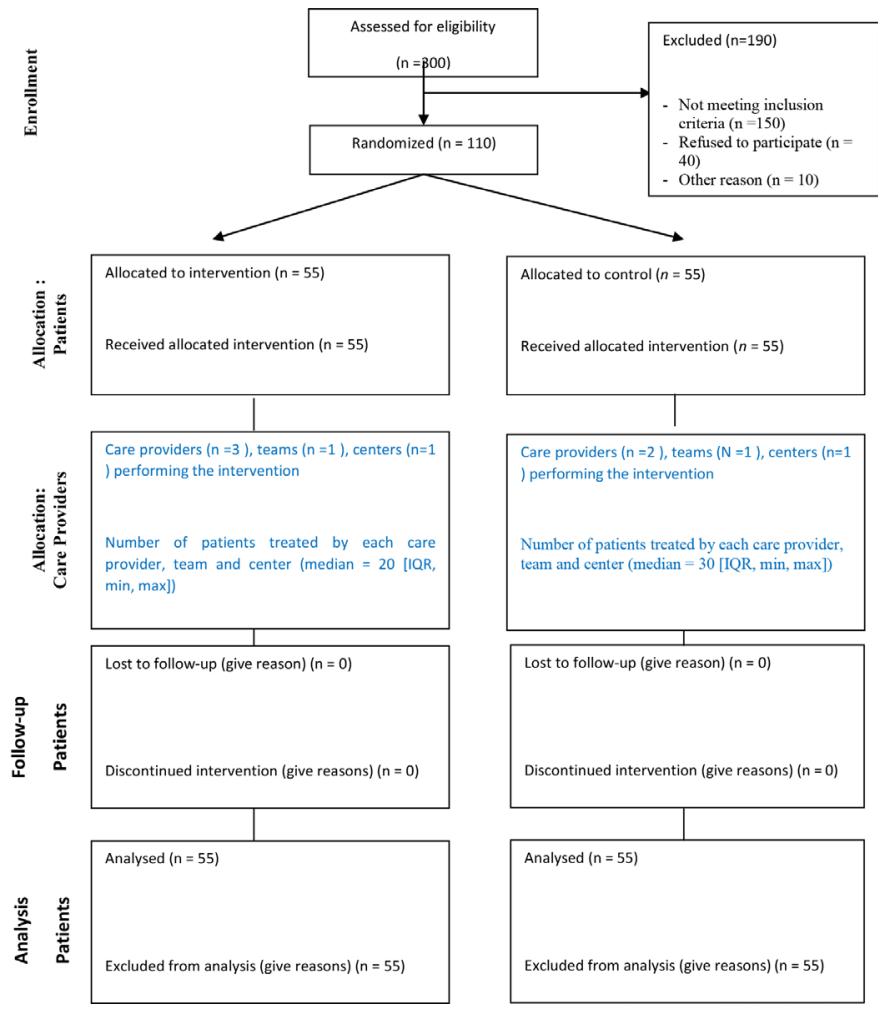

Diagram 1: Modified consort flow diagram for individual randomized controlled trials of nonpharmacologic treatments.

An extra box per intervention group relating to care providers and centers has been added.

$\mathrm{IQR}=$ interquartile range; $\max =$ maximum; $\min =$ minimum

less diploma education. Also, it was the most type of cancer among patients related to gastric, breast and colon cancer (Table 1).

The mean of anxiety score before and after chamomile tea consumption was 23.10 and 17.61, respectively. Also, the mean anxiety score before and after placebo was 22.03 and 21.25 in the control group. A two-sample t-test was performed to compare the effectiveness of the intervention that results demonstrated the mean scores of anxiety before and after intervention in the intervention group were difference significantly $(p<0.001)$. Also, there was a significant difference between the mean scores of anxiety before and after intervention in the control group $(p<0.001)$ (Table 2). The mean of depression scores before and after the intervention in the intervention group was 25.81 and 19.49, respectively. Mean score of depression before and after intervention was 25.83 and 24.90 in control group. Results shows the mean scores of depression before and after intervention in the intervention and control group were difference significantly $(p<0.001)$ (Table 2 ).

Table 3 shows that the benefits to patient cancer of drinking chamomile tea for 2 weeks include significant improvements in the physical symptoms associated with the symptoms of depression. But, no significant differences were identified between the groups in mean score of depression.

The multivariate linear regression analysis was used to compare the effect of base diseases and the duration of cancer on depression and anxiety scores after the intervention. This method and the fact that there is irretrievable wrong between some of the variables meant that the analysis of symptoms could not be controlled for type of cancer, age and gender. This imposes some limitations on the interpretation of the results. Table 4 shows that base disease can have an impact on our results. 
Table 1: Demographics and Clinical Characteristics.

\begin{tabular}{|c|c|c|c|}
\hline Index & & Amount & Percent \\
\hline \multirow[t]{2}{*}{ Sex } & Male & 61 & 55.45 \\
\hline & Female & 49 & 44.55 \\
\hline \multirow[t]{5}{*}{ Age group (Years) } & $20-29$ & 1 & 0.91 \\
\hline & $30-39$ & 12 & 10.91 \\
\hline & $40-49$ & 20 & 18.18 \\
\hline & $50-59$ & 47 & 42.73 \\
\hline & $60-69$ & 30 & 27.27 \\
\hline \multirow[t]{4}{*}{ Education } & Less than a diploma & 35 & 31.82 \\
\hline & Diploma & 14 & 12.73 \\
\hline & Associates Degree & 2 & 1.82 \\
\hline & Bachelor & 3 & 2.73 \\
\hline \multirow{2}{*}{$\begin{array}{l}\text { hospitalized cancer } \\
\text { patients }\end{array}$} & Yes & 55 & 50 \\
\hline & No & 55 & 50 \\
\hline \multirow[t]{5}{*}{ Major disease types } & Diabetes & 19 & 17.27 \\
\hline & Blood pressure & 16 & 14.55 \\
\hline & Kidney disease & 8 & 7.27 \\
\hline & Heart disease & 24 & 21.82 \\
\hline & No disease & 43 & 39 \\
\hline \multirow[t]{9}{*}{ Type of Cancer } & Gastric & 28 & 25.45 \\
\hline & Breast & 27 & 24.55 \\
\hline & Colon & 30 & 27.27 \\
\hline & Esophagus & 3 & 2.73 \\
\hline & Lung & 11 & 10 \\
\hline & Thyroid & 1 & 0.91 \\
\hline & Bone & 3 & 2.73 \\
\hline & Blood & 4 & 3.64 \\
\hline & Liver & 3 & 2.73 \\
\hline
\end{tabular}

Table 2: Two-sample t-tests for outcome variables, experimental and control groups.

$\begin{array}{ccccc}\text { Variable } & & \begin{array}{c}\text { Mean before } \\ \text { intervention }\end{array} & \begin{array}{c}\text { Mean after } \\ \text { intervention }\end{array} & \text { P-value } \\ \text { Anxiety } & \text { Experimental } & 23.10 & 17.61 & <0.001 \\ & \text { Control } & 22.03 & 21.25 & <0.001 \\ \text { Depression } & \text { Experimental } & 25.81 & 19.49 & <0.001 \\ & \text { Control } & 25.83 & 24.90 & <0.001\end{array}$

\section{DISCUSSION}

We found that patient cancer that drank chamomile tea once each day for one week realized significant improvements in their physical-symptoms-related depression. However, these effects of chamomile tea may be short-lived and not used for long periods of time. Chamomile sedative effect is due to the presence of an epinephrine compound that affinity to the central benzodiazepine receptors. ${ }^{13-15}$ The present study also showed that while drinking chamomile tea for two consecutive weeks was effect on decreasing depression in cancer patients, but there was no significant effect on anxiety in patients. However, justifiable mechanism for the effects of chamomile tea on depression in cancer patients is still completely unclear and requires further analysis Chamomile is a biological
Table 3: Two-sample t-tests for outcome variables, experimental and control groups

Before and after intervention.

\begin{tabular}{|c|c|c|c|c|}
\hline \multicolumn{2}{|c|}{ Variable } & \multirow{2}{*}{$\begin{array}{c}\begin{array}{c}\text { Mean } \\
\text { experimental } \\
\text { group }\end{array} \\
23.10\end{array}$} & \multirow{2}{*}{$\begin{array}{c}\begin{array}{c}\text { Mean control } \\
\text { group }\end{array} \\
22.03\end{array}$} & \multirow{2}{*}{$\begin{array}{c}P \text {-value } \\
0.71\end{array}$} \\
\hline Anxiety & $\begin{array}{c}\text { Before } \\
\text { intervention }\end{array}$ & & & \\
\hline & $\begin{array}{c}\text { After } \\
\text { intervention }\end{array}$ & 17.61 & 21.25 & 0.18 \\
\hline \multirow[t]{2}{*}{ Depression } & $\begin{array}{c}\text { Before } \\
\text { intervention }\end{array}$ & 25.81 & 25.83 & 0.99 \\
\hline & $\begin{array}{c}\text { After } \\
\text { intervention }\end{array}$ & 19.49 & 24.90 & 0.003 \\
\hline
\end{tabular}

Table 4: Logistic regression analysis to comparison the effect of interventional variables (tea and placebo) on depression and anxiety.

\begin{tabular}{cccc} 
& B & p-value & $\begin{array}{c}95 \% \text { Confidence } \\
\text { Interval }\end{array}$ \\
\hline $\begin{array}{c}\text { Anxiety } \\
\text { Group (experimental and } \\
\text { control) } \\
\begin{array}{c}\text { Depression } \\
\text { Group experimental and } \\
\text { control)) }\end{array}\end{array}$ & 4.16 & 0.13 & $(-1.35-9.68)$ \\
\hline
\end{tabular}

profile. An interpretation that can be considered for this effect relates to a mechanism of action similar to non-steroidal, anti-inflammatory drugs as mentioned in the references. ${ }^{16}$

Considering the variety of cancer cases studied in this study, disease stage, perceived treatment effect and functional status effect on anxiety and depressive symptoms. ${ }^{8}$ Also, those who were not sure about the effects of their treatment were probably more anxious and depressed than those who thought their condition had improved. ${ }^{8}$ Functional status of patients, including the patient's ability to tolerate the pain may have an impact extent the results of this study. So that those who received less pain relief during the previous week were more depressed and anxiety. Chang et al. (2015) a clinical trial that was performed on 80 women after childbirth studied chamomile tea effect on sleep quality, depression and sleep disorders. Patients in the intervention group consumed chamomile tea once a day for 2 weeks and only normal care was taken in the control group, then the questionnaires were completed again. The results showed that chamomile tea can be beneficial for depression, sleep quality and sleep disturbance. ${ }^{17}$ The differences between our results and the findings of Chang et al. confirm that any cancer patient has a different response to chamomile tea treatment. Also in another study, Mao et al. (2016) evaluated long-term chamomile (Matricaria chamomilla L.) for prevention of generalized anxiety disorder symptom relapse that result showed longterm chamomile was harmless and significantly reduced moderate-tosevere generalized anxiety disorder symptoms, but did not significantly reduce rate of relapse that result opposite with our study. ${ }^{18} \mathrm{~A}$ possible interpretation may be related to consumption chamomile tea for 12 weeks, while in our study was 2 weeks. Probably Chamomile effect is most significant in the long-term on anxiety. Amsterdam et al. (2016) studied effect of chamomile extract standardised to reducing anxiety symptoms in individuals $(n=57)$ diagnosed with generalized anxiety disorder. Although this study gives evidence for efficacy of chamomile in reducing anxiety, but the most effective dosage remains uncertain that the results were in agreement with our results. 
The anti-depressant effect of chamomile is still not completely understood, although it may be independent of anxiolytic activity. Several lines of evidence recommend that one or more of chamomile's flavanoid constituents may exert an antidepressant effect via modulation of central noradrenalin, dopamine, serotonin and $\gamma$-amino butyric acid neurotransmission. ${ }^{19-21}$

\section{CONCLUSION}

These findings verified that drinking chamomile tea once each day for a 2-week period has positive and significant effects on depression but no effect on anxiety observed in patient cancer. Chamomile tea can be used as an alternative treatment to depression therapy in cancer patients undergoing chemotherapy due to its low, safe, simple and affordable side effects. Chamomile tea is recommended for cancer patients undergoing chemotherapy as an effective way to reduce symptoms of depression. In addition, we hope that health care professionals evaluate these findings in order to raise awareness about the positive use of medicinal plants in treating the complications of chemotherapy in cancer patients.

\section{ACKNOWLEDGEMENT}

The Neishabour University of Medical Sciences, Iran financially supported this work. We also thank the Shahsavand Co. (Tehran, Iran) for providing chamomile tea for the study. We thank the participants for their help in making this study possible.

\section{Funding}

This study was funded by Grant from the Neishabour University of Medical Sciences, Iran.

\section{CONFLICT OF INTEREST}

The authors declare no conflict of interest.

\section{REFERENCES}

1. Black R, Bray F, Ferlay J, Parkin D. Cancer incidence and mortality in the European Union: Cancer registry data and estimates of national incidence for 1990. Eur J Cancer. 1997;33(7):1075-7.

2. Ries L, Eisner M, Kosary C, Hankey B, Miller B, Clegg L, et al. SEER Cancer Statistics Review 1973-1999. National Cancer Institute. Bethesda, MD. 2002. NIH publications no. 00-2789; 2008.
3. Chang C, Bresnahan B, Gagnon D, Lent L, Zagari M, McNulty P, et al. Crosslanguage validation of the Functional Assessment of Cancer Therapy-Anemia (FACT-AN) questionnaire. Eur J Cancer. 1999;35:S359.

4. Lindley C, Vasa S, Sawyer WT, Winer EP. Quality of life and preferences for treatment following systemic adjuvant therapy for early-stage breast cancer. J Clin Oncol. 1998;16(4):1380-7.

5. Carelle N, Piotto E, Bellanger A, Germanaud J, Thuillier A, Khayat D. Changing patient perceptions of the side effects of cancer chemotherapy. Cancer. 2002;95(1):155-63.

6. Love RR, Leventhal H, Easterling DV, Nerenz DR. Side effects and emotional distress during cancer chemotherapy. Cancer. 1989:63(3):604-12.

7. Lerman C, Rimer B, Blumberg B, Cristinzio S, Engstrom PF, MacElwee N, et al. Effects of coping style and relaxation on cancer chemotherapy side effects and emotional responses. Cancer Nurs. 1990;13(5):308-15.

8. Chen $\mathrm{ML}$, Chang HK, Yeh $\mathrm{CH}$. Anxiety and depression in Taiwanese cancer patients with and without pain. J Adv Nurs. 2000;32(4):944-51.

9. Wang Y, Tang H, Nicholson JK, Hylands PJ, Sampson J, Holmes E. A metabonomic strategy for the detection of the metabolic effects of chamomile (Matricaria recutita L.) ingestion. J Agric Food Chem. 2005;53(2):191-6.

10. McKay DL, Blumberg JB. A review of the bioactivity and potential health benefits of peppermint tea (Mentha piperita L.). Phytother Res. 2006;20(8):619-33.

11. Srivastava JK, Gupta S. Antiproliferative and apoptotic effects of chamomile extract in various human cancer cells. J Agric Food Chem. 2007:55(23):9470-8.

12. Beck AT, Epstein N, Brown G, Steer RA. An inventory for measuring clinical anxiety: Psychometric properties. J Consult Clin Psychol. 1988;56(6):893.

13. Viola $H$, Wasowski $C$, DeStein ML, Wolfman C, Silveira R, Dajas F, et al Apigenin, a component of Matricaria recutita flowers, is a central benzodiazepine receptors-ligand with anxiolytic effects. Planta Med. 1995;61(03):213-6.

14. Cherniack EP. The use of alternative medicine for the treatment of insomnia in the elderly. Psychogeriatrics. 2006;6(1):21-30.

15. Tschiggerl C, Bucar F. Guaianolides and volatile compounds in chamomile tea. Plant Food Hum Nutr. 2012;67(2):129-35.

16. Srivastava JK, Gupta S. Health promoting benefits of chamomile in the elderly population. Complementary and Alternative Therapies and the Aging Population: Elsevier. 2009;135-58.

17. Chang $\mathrm{SM}, \mathrm{Chen} \mathrm{CH}$. Effects of an intervention with drinking chamomile tea on sleep quality and depression in sleep disturbed postnatal women: A randomized controlled trial. J Adv Nurs. 2016;72(2):306-15.

18. Mao JJ, Xie SX, Keefe JR, Soeller I, Li QS, Amsterdam JD. Long-term chamomile (Matricaria chamomilla L.) treatment for generalized anxiety disorder: A randomized clinical trial. Phytomedicine. 2016;23(14):1735-42.

19. Morita K, Hamano S, Oka M, Teraoka K. Stimulatory actions of bioflavonoids on tyrosine uptake into cultured bovine adrenal chromaffin cells. Biochem Biophys Res Commun. 1990;171(3):1199-204.

20. Nakazawa T, Yasuda T, Ueda J, Ohsawa K. Antidepressant-like effects of apigenin and 2, 4, 5-trimethoxycinnamic acid from Perilla frutescens in the forced swimming test. Biol Pharm Bull. 2003;26(4):474-80.

21. Anjaneyulu M, Chopra K, Kaur I. Antidepressant activity of quercetin, a bioflavonoid, in streptozotocin-induced diabetic mice. J Med Food. 2003;6(4):391-5.

Article History: Submission Date : 09-06-2019; Revised Date : 28-06-2019; Acceptance Date : 16-07-2019.

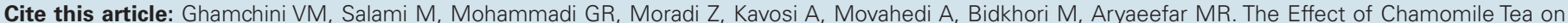
Anxiety and Depression in Cancer Patients Treated with Chemotherapy. J Young Pharm. 2019;11(3):309-12. 